\title{
Midfacial development and the wisdom of teeth: A case series
}

\author{
G. Dave Singh ${ }^{1}$ and Sangmin Lee ${ }^{2}$ \\ ${ }^{1}$ Vivos Therapeutics, Inc. \\ ${ }^{2}$ Dental Office
}

September 25, 2021

\begin{abstract}
The alignment of third molars has largely been overlooked by orthodontists. Since difficulties arise during their eruption, a plethora of surgical procedures is advocated for their management, including prophylactic extraction. This case series describes the use of midfacial development in 4 patients and illustrates successful patterns of third molar eruption.
\end{abstract}

\section{Introduction}

The routine surgical removal of asymptomatic third molars has almost become a rite of passage in many countries. On the other hand, alignment of the remaining dentition has been addressed with special emphasis on the 'social six' upper anterior teeth [1]. The reasons for these trends are varied and complex but likely have an historical basis since medical complications emanating from partially-erupted and/or impacted third molars were first reported over century ago [2]. In fact, impacted third molars have a prevalence of approx. $18-32 \%$ in modern humans, which makes assessment of their eruptive prognosis mandatory [3] because of complications associated with them. Recently, Malanchuk et al. [4] confirmed local pathologic processes, which precede caries as well as inflammation of the soft tissues and the adjacent alveolar bone, to justify surgical attenuation of the (lower) third molars. A systematic review [5] had also reported that pathologies related to third molar retention include caries, periodontal diseases, second molar root resorption, and pericoronitis. In addition, Cederhag et al. [6] evaluated the anatomic relations of the lower third molars with respect to the inferior alveolar nerve using panoramic radiographs. They reported that their roots were located above the inferior alveolar nerve in about half $(52 \%)$ of the cases examined. However, while panoramic radiography is extensively used for diagnosis and preoperative treatment planning, the predictive value of this data remains ambiguous. In this regard, Vranckx et al. [7] assessed radiologic risk indicators and postoperative morbidity in patients undergoing upper and/or lower third molar exodontia. They noted that severe impactions were associated with postoperative pain, trismus and swelling with a need for pain medication. However, when the ability to identify the risk of third molar non-eruption using panoramic radiographic analysis was evaluated, Libdy et al. [8] found that both orthodontists and oral maxillofacial surgeons were unable to predict which third molars would become impacted; both groups of specialists indicated extractions in approx. $50 \%$ of cases, being unable to distinguish those in which the third molars would erupt normally.

To prevent future dental pathology of adjacent teeth, the prophylactic extraction of asymptomatic third molars is commonly advocated. However, in a series of three cases [9] periodontal attachment loss and serious damage of the adjoining second molar was reported, while a third patient suffered post-operative osteomyelitis and fracture of the angle of the mandible during prophylactic exodontia. In addition, the extraction procedure is sometimes associated with damage of the inferior alveolar nerve when the tooth roots are anatomically adjacent to it, resulting in sensory dysfunction, such as paresthesia. Repass [10] was one of the first to describe the inferior dental nerves passing through the roots of impacted mandibular 
third molars. Furthermore, mandibular fractures are also a relatively common risk and represent a serious post-operative complication. Beret et al. [11] evaluated mandibular fracture complications of impacted lower third molars, which included post-operative malocclusion, mouth opening limitation, inferior alveolar nerve paresthesia, infection, delayed bony union, and loosening of surgically-placed hardware. To avoid the risks of post-operative morbidity and injury, coronectomy has become more common. However, one of the sequelae of coronectomy is eruption of the retained root, and Steinberg et al. [12] described a case in which the retained root displaced the inferior alveolar nerve, resulting in neurologic symptoms. Thus, as unerupted third molars rarely remain pathology-free, new approaches are needed to address their clinical management. Therefore, the aim of this study is to describe a series of cases treated by a general dentist using the DNA appliance (Vivos Therapeutics, Inc., USA) that putatively increases midfacial bone volume [13] as an alternative technique in the clinical management of unerupted third molars.

\section{Case Reports}

This study was conducted under the standards required by the Declaration of Helsinki. All individuals gave written/oral informed consent prior to their inclusion in this study.

\section{Case 5535}

A 21-year-old male attended the dental office with an initial chief complaint concerning temporo-mandibular dysfunction (TMD). History-taking revealed he had been treated for TMD for about 18 months by a different specialist, but little progress had been made with the symptoms. The patient was worried about the TMD as well as his prognathic facial profile. He had been advised about the possibility of orthognathic surgery and third molar extractions but was seeking a non-surgical alternative. After receiving informed consent, physical examination was undertaken as well as panoral radiography (Fig. 1). A working diagnosis of Class III malocclusion with midfacial hypoplasia, with a differential diagnosis of TMD, was reached. The treatment plan included midfacial development to enhance the functional space available for the mandible in an effort to relieve the TMD discomfort and balance the facial profile. A biomimetic oral device (DNA appliance, Vivos Therapeutics, Inc. USA) was prescribed to meet these requirements (Fig. 2) with a Y-split design without second molar coverage. The device was worn for 10-16 hrs. per day, including while sleeping, but not while eating. Gradual adjustments were made to the appliance approx. every 4-6 wks. Treatment started in 2014 and gradually the TMD symptoms regressed. In addition, the third molars erupted into occlusion (Fig. 3). The patient was satisfied with this approach and the treatment appeared to be stable after approx. 7yrs. (Fig. 4).

\section{Case 8467}

A 24-year-old female attended the dental office with an initial chief complaint concerning pain in the lower left quadrant. Medical history-taking was unremarkable. After receiving informed consent, physical examination was undertaken as well as a panoramic radiograph (Fig. 5). A working diagnosis of gross caries at tooth \#18 with a differential diagnosis of impacted third molars was reached (Fig. 5). The treatment plan included endodontic and restorative procedures for tooth \#18. Treatment started in 2016 and the dental treatment relived the pain. The patient was informed about the possibility of recurrent pain from the unerupted molars and after considering the risks, benefits and alternatives, she elected on biomimetic oral appliance therapy. In this case, the upper device also had a Y-split design without second molar coverage (Fig. 2). The device was worn for approx. 10-16 hrs. per day, including while sleeping, but not while eating. Gradual adjustments were made to the appliance approx. every $4-6$ wks. The lower device (Fig. 6) was instituted approx. 3mos. later. Treatment with the devices was finished after about 2yrs. in 2018. Panoral radiography confirmed that all the third molars were fully erupted (Fig. 7). The case was finished with standard orthodontic brackets.

\section{Case 3044}

A 9-year-old male attended the dental office with his parents who had an initial chief complaint concerning his anterior open bite tendency (Fig. 8). History-taking was unremarkable and the parents were counseled about the possibility of their child needing orthognathic surgery after maturation. However, they preferred a 
preventive, non-invasive alternative. After receiving informed consent, physical examination was undertaken as well as a panoral radiograph (Fig. 9), which revealed that the tooth germs for $\# 1$ and \#16 were not identifiable. A working diagnosis of apertognathia with midfacial hypoplasia was reached. The patient started treatment with fixed orthodontic brackets, including a facemask and elastics, but progress was slow. Therefore, the treatment plan was modified to include midfacial development. An upper biomimetic oral device was deployed and gradually the anterior open bite improved (Fig. 10). A lower Wireframe DNA appliance (Fig. 11) was used to re-coordinate the lower arch with changes in the upper arch. The case was finished with standard orthodontic brackets. In this patient, tooth \#16 was found to be congenitally absent but using this biomimetic protocol the other three third molars erupted into occlusion (Fig. 12). The patient was advised to continue with oral myofunctional therapy exercises to retain the stability of the outcome.

\section{Case 6640}

A 22-year-old female attended the dental office with an initial chief complaint concerning her facial appearance (bimaxillary protrusion). Medical history-taking revealed a history of headaches and fainting with a suspicion of Moyamoya disease, which includes chronic and progressive narrowing of the intra-cranial arteries. Despite these findings, informed consent was obtained, and physical examination was undertaken followed by panoramic radiography (Fig. 13). A working diagnosis of bialveolar protrusion was reached. The treatment plan included extraction of four first premolars and the use of headgear for arch retraction with fixed orthodontics and mini screws to enhance the facial profile. After premolar extractions, her upper lip appeared to become rather thin, impacting the facial profile negatively (Fig. 14). Therefore, fixed orthodontic treatment was not initiated but to counteract this unwanted side effect, the patient elected on biomimetic oral appliance therapy instead. The patient was treated with an upper biomimetic device prior to a lower device being delivered approx. 3 mos. later. This treatment started in 2016 and gradually the facial profile improved (Fig. 15). Moreover, the third molars were now fully erupted (Fig. 16). At this stage, fixed appliance therapy was reinstituted to close the premolar extraction spaces.

\section{Discussion}

The patho-etiology of unerupted third molars remains unresolved and controversial. In a recent study [14] it was found that over half $(52 \%)$ of adults above 18 years had at least one impacted third molar regardless of the skeletal/dental antero-posterior relationship. Some have suggested that as modern humans evolved the jaws became diminutive, leading to end-molar impaction. However, evolutionary history suggests that the teeth became larger in size through an increased number of cusps [15] with thicker enamel [16]. Recently, Olsson et al. [17] reported that although the MSX1 gene is expressed differently for impacted maxillary third molars, in general, other changes in gene expression are not found, suggesting an epigenetic mechanism for third molar impaction. Similarly, Isomura et al. [18] concluded that while third molar eruption was more similar in monozygotic twins compared to dizygotic twins, the identification of genetic trends, such as those encoding for reduced stature, influence third molar treatment options. In fact, Adeyemo et al. [19] found that subjects with lower third molar impactions were often shorter in height. In a similar study [20], insufficient bony dimensions for the eruption of the third molars were found in teenagers with Class II malocclusions. Because of these concepts, some believe that extraction of other teeth can result in favorable treatment outcomes for third molars [21]. In our present study, Case \#6640 appears to support this approach. After the extraction of four, healthy, first premolars, biomimetic oral appliance therapy appears to have aided in the eruption of the third molars in an adult aged 22yrs at the beginning of treatment. Indeed, although the early extraction of healthy teeth is debatable given the uncertainty of the developing third molars erupting, it is essential to assess the third molars' eruptive potential and provide sufficient functional space. Park et al. [22] reported spontaneous eruption of a third molar after extraction of an ankylosed mandibular first molar. In that case, orthodontic intrusion of the maxillary first molar and mesialization of the root of the second molar was completed before third molar root formation.

While a deficiency of retromolar space is a known risk factor for end-molar impaction, Marchiori et al. [23] investigated delayed third molar development as a factor leading to impacted wisdom teeth. They found that a lack of jaw space distal to the second molars was related to less well-developed third molars, and a 
severe deficiency of space was associated with an absence of third molar tooth germ development in early childhood. In our study, for case \#3044 (a 9-year-old male), panoral radiography revealed the absence of developing \#1 and \#16 tooth germs (Fig. 9). By the end of treatment, however, while tooth \#16 was found to be congenitally absent, the other three third molars erupted into occlusion (Fig. 12). This somewhat surprising outcome might be associated with the use of biomimetic oral appliance therapy, which putatively increases midfacial bone volume [13]. Tamer et al. [24] consider eruptive issues associated with third molars ought to be diagnosed and treated early, using orthodontic repositioning, surgical uprighting or extractions (with or without transplantation). In this way, induced third molar eruption was reported by Jung et al. [25]. However, in that case they utilized a mini-screw placed in the maxilla with cross-arch elastics to induce eruption prior to exodontia, which contrasts with the biomimetic approach described in this case, since the third molars erupted naturally and did not require extraction. Therefore, treatment timing is an essential factor in the management of third molars.

There is a dearth of literature on the use of devices to recapture retromolar space to aid in the eruption of third molars. One study [25] compared mandibular third molar eruption in teenagers with Class II malocclusions using a Forsus device. They found that the device led to mesialization of the lower arch, which increased the retromolar space but there was only little uprighting of the third molars. In contrast, using biomimetic oral appliance therapy, both Case \#5535 and Case \#8476 showed eruption of the third molars in all four quadrants (Fig. 4 and Fig. 7, respectively). Indeed, both of these cases initially presented to the dental office with craniofacial pain. Mksoud et al [26] investigated the correlation of orofacial pain, jaw muscle pain, headache/migraine to third molar eruption status. They reported that although impacted third molars are not associated with masticatory muscle pain or migraines headaches, they can be a cause of chronic orofacial pain. Indeed, in our study, Case \#5535 was concerned with TMJ issues and Case \#8476 had gross caries masking and/or masquerading as third molar odontalgia. Both of these cases showed resolution of craniofacial pain and spontaneous eruption of the third molars (Fig. 4 and Fig. 7, respectively). Indeed, De Bruyn et al. [28] include adequate eruptive space as one reason for retaining third molar teeth since approx. one third (32\%) can erupt into proper occlusion. Therefore, this case series describes the use of a novel, biomimetic midfacial development protocol to illustrate how successful patterns of third molar eruption might be achieved. Further studies are now indicated to test the robustness of these initial findings.

\section{Acknowledgements}

The authors would like to thank STAA Orthodontic Laboraory, Seoul, South Korea for fabricating the devices used in this study. No funding was received for this study.

\section{References}

1. Björksved M, Arnrup K, Bazargani SM, Lund H, Magnusson A, Magnuson A, Lindsten R, Bazargani F. 2021. Open vs closed surgical exposure of palatally displaced canines: a comparison of clinical and patient-reported outcomes-a multicentre, randomized controlled trial. European Journal of Orthodontics Jun 11:cjab015. doi: 10.1093/ejo/cjab015. Epub ahead of print.

2. Anonymous. 1882. Difficulties arising from eruption of a third molar. Dental Register 36: 409-410.

3. KalaiSelvan S, Ganesh SKN, Natesh P, Moorthy MS, Niazi TM, Babu SS. 2020. Prevalence and pattern of impacted mandibular third molar: An institution-based retrospective study. Journal of Pharmacology Bioallied Science 12(Suppl 1): S462-S467.

4. Malanchuk VA, Volovar OS, Oblap MV, Brodetskyi IS, Dobryi-Vechir TV, Hryhorovskyi VV, Brodetska LO, Dyadyk OO, Myroshnychenko MS. 2021. Clinical and morphological correlation dependencies and their significance in patients with complications of labored eruption of the lower third molars. Wiadomości Lekarskie 74:441-449.

5. Vandeplas C, Vranckx M, Hekner D, Politis C, Jacobs R. 2020. Does retaining third molars result in the development of pathology over time? A systematic review. Journal of Oral and Maxillofacial Surgery 78:1892-1908.

6. Cederhag J, Lundegren N, Alstergren P, Shi XQ, Hellén-Halme K. 2020. Evaluation of panoramic radiographs in relation to the mandibular third molar and to incidental findings in an adult population. 
European Journal of Dentistry 15:266-272.

7. Vranckx M, Lauwens L, Moreno Rabie C, Politis C, Jacobs R. 2021. Radiological risk indicators for persistent postoperative morbidity after third molar removal. Clinical Oral Investigations 2021 Jan 3. doi: 10.1007/s00784-020-03759-7. Epub ahead of print.

8. Libdy MR, Rabello NM, Marques LS, Normando D. 2020. The ability of orthodontists and maxillofacial surgeons in predicting spontaneous eruption of mandibular third molar using panoramic serial radiographs. Dental Press Journal of Orthodontics 25:68-74.

9. Ghaeminia H, Hover R, Hoppenreijs TJM. 2020. Asymptomatic third molars; To remove or not to remove? (Article in Dutch). Nederlands tijdschrift voor tandheelkunde 127:409-416.

10. Repass FG. 1946. Impacted right and left mandibular third molars with inferior dental nerves passing through the mesial roots; report of case. Journal of Oral Surgery (Chicago) 4:243.

11. Beret M, Nicot R, Roland-Billecart T, Ramdane N, Ferri J, Schlund M. 2021. Impacted lower third molar relationship with mandibular angle fracture complications. Journal of Stomatology and Oral and Maxillofacial Surgery May 15:S2468-7855(21)00114-2. doi: 10.1016/j.jormas.2021.05.004. Epub ahead of print.

12. Steinberg MJ, Nick MJ. 2021. Displacement of the inferior alveolar bundle secondary to post coronectomy root migration: A case report. Journal of Oral and Maxillofacial Surgery May 7:S02782391(21)00333-5. doi: 10.1016/j.joms.2021.04.012. Epub ahead of print.

13. Singh GD, Heit T, Preble D. 2014. Changes in 3D midfacial parameters after biomimetic oral appliance therapy in adults. Journal of the Indian Orthodontic Society 48:100-104.

14. Jain S, Debbarma S, Prasad SV. 2019. Prevalence of impacted third molars among orthodontic patients in different malocclusions. Indian Journal of Dental Research 30:238-242.

15. Jørgensen KD. 1955. The Dryopithecus pattern in recent Danes and Dutchmen. Journal of Dental Research 34:195-208.

16. Beynon AD, Wood BA. 1986. Variations in enamel thickness and structure in East African hominids. American Journal of Physical Anthropology 70:177-193.

17. Olsson B, Calixto RD, da Silva Machado NC, Meger MN, Paula-Silva FWG, Rebellato NLB, da Costa DJ, Küchler EC, Scariot R. 2020. MSX1 is differentially expressed in the deepest impacted maxillary third molars. British Journal of Oral and Maxillofacial Surgery 58:789-794.

18. Isomura ET, Kurushima Y, Kobashi H, Enoki K, Yamashita M, Ikebe K. 2020. Osaka twin research group. Factors influencing the localization of mandibular third molars in twins. Journal of Oral and Maxillofacial Surgery 78:1279-1287.

19. Adeyemo WL, James O, Oladega AA, Adamson OO, Adekunle AA, Olorunsola KD, Busch T, Butali A. 2021. Correlation between height and impacted third molars and genetics role in third molar impaction. Journal of Maxillofacial and Oral Surgery 20:149-153.

20. Bozkaya E, Kaygisız E, Tortop T, Güray Y, Yüksel S. 2020. Mandibular posterior space in class II division 1 and 2 malocclusion in various age groups. Journal of Orofacial Orthopedics 81:249-257.

21. Jackson K, Ong D, Freer E. 2020. Spontaneous eruption of maxillary third molars in the adult patient undergoing orthodontic treatment after first molar extractions. Clinical Case Reports 8:1392-1398.

22. Park SH, Koo YJ, Keum BT, Chun JH, Lee KJ. 2021. Early replacement of ankylosed first molar via mesial root movement facilitates bone formation and normal eruption of the third molar. Angle Orthodontist Mar 22. doi: 10.2319/081720-723.1. Epub ahead of print.

23. Marchiori DF, Packota GV, Boughner JC. 2019. Initial third molar development is delayed in jaws with short distal space: An early impaction sign? Archives of Oral Biology 106:104475

24. Tamer İ, Öztaş E, Marşan G. 2020. Up-to-date approach in the treatment of impacted mandibular molars: A literature review. Turkish Journal of Orthodontics 33:183-191.

25. Jung S, Lee JH, Huh J, Park W. 2021. Orthodontic extrusion of mandibular third molar with a miniscrew and cross-arch elastic. Journal of Oral and Maxillofacial Surgery Feb 7:S0278-2391(21)00104X. doi: 10.1016/j.joms.2021.01.036. Epub ahead of print.

26. Aslan BI, Akarslan ZZ, Karadă̆ Ö. 2021. Effects of Angle class II correction with the Forsus fatigue resistant device on mandibular third molars : A retrospective study. Journal of Orofacial Orthopedics 
Mar 5. doi: 10.1007/s00056-021-00281-7. Epub ahead of print.

27. Mksoud M, Ittermann T, Daboul A, Schneider P, Bernhardt O, Koppe T, Bülow R, Metelmann HR, Völzke H, Kindler S. 2020. Are third molars associated with orofacial pain? Findings from the SHIP study. Community, Dental and Oral Epidemiology 48:364-370.

28. De Bruyn L, Vranckx M, Jacobs R, Politis C. 2020. A retrospective cohort study on reasons to retain third molars. International Journal of Oral and Maxillofacial Surgery 49:816-821.

\section{Conflict of Interest Statement}

Professor Singh is the Founder and Chief Medical Officer of Vivos Therapeutics, Inc. USA.

\section{Hosted file}

Fig. 1.pptx available at https://authorea.com/users/437631/articles/539129-midfacialdevelopment-and-the-wisdom-of-teeth-a-case-series

\section{Hosted file}

Fig. 2.pptx available at https://authorea.com/users/437631/articles/539129-midfacialdevelopment-and-the-wisdom-of-teeth-a-case-series

\section{Hosted file}

Fig. 3a.pptx available at https://authorea.com/users/437631/articles/539129-midfacialdevelopment-and-the-wisdom-of-teeth-a-case-series

\section{Hosted file}

Fig. 3b.pptx available at https://authorea.com/users/437631/articles/539129-midfacialdevelopment-and-the-wisdom-of-teeth-a-case-series

\section{Hosted file}

Fig. 3c.pptx available at https://authorea.com/users/437631/articles/539129-midfacialdevelopment-and-the-wisdom-of-teeth-a-case-series

\section{Hosted file}

Fig. 3d.pptx available at https://authorea.com/users/437631/articles/539129-midfacialdevelopment-and-the-wisdom-of-teeth-a-case-series

\section{Hosted file}

Fig. 4.pptx available at https://authorea.com/users/437631/articles/539129-midfacialdevelopment-and-the-wisdom-of-teeth-a-case-series

\section{Hosted file}

Fig. 5.pptx available at https://authorea.com/users/437631/articles/539129-midfacialdevelopment-and-the-wisdom-of-teeth-a-case-series

\section{Hosted file}

Fig. 6.pptx available at https://authorea.com/users/437631/articles/539129-midfacialdevelopment-and-the-wisdom-of-teeth-a-case-series

\section{Hosted file}

Fig. 7.pptx available at https://authorea.com/users/437631/articles/539129-midfacialdevelopment-and-the-wisdom-of-teeth-a-case-series

\section{Hosted file}


Fig. 8.pptx available at https://authorea.com/users/437631/articles/539129-midfacialdevelopment-and-the-wisdom-of-teeth-a-case-series

\section{Hosted file}

Fig. 9.pptx available at https://authorea.com/users/437631/articles/539129-midfacialdevelopment-and-the-wisdom-of-teeth-a-case-series

\section{Hosted file}

Fig. 10.pptx available at https://authorea.com/users/437631/articles/539129-midfacialdevelopment-and-the-wisdom-of-teeth-a-case-series

\section{Hosted file}

Fig. 11.pptx available at https://authorea.com/users/437631/articles/539129-midfacialdevelopment-and-the-wisdom-of-teeth-a-case-series

\section{Hosted file}

Fig. 12.pptx available at https://authorea.com/users/437631/articles/539129-midfacialdevelopment-and-the-wisdom-of-teeth-a-case-series

\section{Hosted file}

Fig. 13.pptx available at https://authorea.com/users/437631/articles/539129-midfacialdevelopment-and-the-wisdom-of-teeth-a-case-series

\section{Hosted file}

Fig. 14.pptx available at https://authorea.com/users/437631/articles/539129-midfacialdevelopment-and-the-wisdom-of-teeth-a-case-series

\section{Hosted file}

Fig. 15.pptx available at https://authorea.com/users/437631/articles/539129-midfacialdevelopment-and-the-wisdom-of-teeth-a-case-series

\section{Hosted file}

Fig. 16.pptx available at https://authorea.com/users/437631/articles/539129-midfacialdevelopment-and-the-wisdom-of-teeth-a-case-series 